\title{
RFID in textile and clothing manufacturing: technology and challenges
}

\author{
Rajkishore Nayak, Amanpreet Singh, Rajiv Padhye ${ }^{*}$ and Lijing Wang
}

\author{
${ }^{*}$ Correspondence: \\ rajiv.padhye@rmit.edu.au \\ School of Fashion \\ and Textiles, RMIT University, \\ Melbourne, Australia
}

\begin{abstract}
In the field of textile and clothing, radio frequency identification (RFID), which is one of the most promising technological innovations, is used in manufacturing, inventory control, warehousing, distribution, logistics, automatic object tracking and supply chain management. Various retailers and manufacturers (of clothing as well as consumer goods) such as CVS, Tesco, Prada, Benetten, Wal-mart and Procter \& Gamble, are now implementing the technology and exploring the impact of the technology on their business. RFID technologies may improve the potential benefits of supply chain management through reduction of inventory losses, increase of the efficiency and speed of processes and improvement of information accuracy. The basic of success lies in understanding the technology and other features to minimize the potential problems. Although the technology existed for several years, the technological challenges and cost issues are the major hurdles for the widespread use of RFID. In this paper, the authors have addressed the technology of RFID and various applications related to inventory management, production control, retail management, brand segregation etc. in textile and clothing industry. In addition, the disadvantages, challenges and future directions of RFID technology have also been highlighted.
\end{abstract}

Keywords: RFID, Fashion, Textiles, Supply chain management, Inventory, Retail

\section{Introduction}

The rapid pace at which the technological innovations are being introduced in the world poses a potential challenge to the retailer, supplier, and enterprises. In the field of Information Technology (IT) there is a rapid growth in the last 30 years (Want 2006; Landt 2005). One of the most promising technological innovations in IT is radio frequency identification (RFID) (Dutta et al. 2007; Whitaker et al. 2007; Bottani et al. 2009). The RFID technology was evolved in 1945 as an espionage tool invented by Leon Theremin for the Soviet Government (Nikitin et al. 2013, Tedjini et al. 2012). At that time it was mainly used by the military. The progress in microchip design, antenna technology and radio spread spectrum pushed it into various applications like supply chain management, retail, automatic toll collection by tunnel companies, animal tracking, ski lift access, tracking library books, theft prevention, vehicle immobilizer systems, railway rolling stock identification, movement tracking, security, healthcare, printing, textiles and clothing (Weinstein 2005; Liu and Miao 2006; Rao et al. 2005; Wu et al. 2009; Tan 2008). RFID can make the companies more competitive by changing the related processes in supply chain, manufacturing and retailing.

() 2015 Nayak et al. This article is distributed under the terms of the Creative Commons Attribution 4.0 International License (http:// creativecommons.org/licenses/by/4.0/), which permits unrestricted use, distribution, and reproduction in any medium, provided you give appropriate credit to the original author(s) and the source, provide a link to the Creative Commons license, and indicate if changes were made. 
The RFID and bar coding systems resemble in the concept of identifying different objects (White et al. 2007; Dos Santos and Smith 2008). However, RFID enhances data processing and works as a complementary to the existing technologies. RFID is the advanced system over barcodes in terms of non-optical proximity communication, information density and two-way communication ability (Roberts 2006; Nath et al. 2006; Miles et al. 2008). The recent developments in microelectronics and data processing have enabled the use of less expensive and smaller components with improved efficiency of RFID. Hence, the application of RFID in various areas particularly in supply chain has grown from $\$ 1$ billion in 2003 to $\$ 20$ billion in 2013 (Bagchi et al. 2007). The recent research works on RFID focus on inventory management, logistics, transportation, manufacturing, asset tracking and object location (Piramuthu et al. 2014; Sun 2012; García et al. 2007; Nayak and Padhye 2015a).

World trade organisation (WTO) is continuously thriving to facilitate international trade by reducing barriers which assists the manufacturing process of fashion products to low cost countries. Christopher characterizes the fashion industry by wider collection/more choices, seasonally impacted, variable and short life-cycles, complex supply chain and distribution activities (Christopher et al. 2004). Profitability in fashion industries are going down due to the competitive nature of business, thus requiring better coordination between all the partners in supply chain. Fashion companies dominating the market at some stage have lost their market share to the emerging companies like Zara, H\&M and Benetton as the business strategy of these companies' involves more inventory turns and they offer wider range of assortments giving rise a concept of "Fast Fashion". All these changes in fashion industry need to capture new technologies and using them wisely, which can reduce lead time, cost and most importantly efficiently manage the inventory. Among the new technologies, RFID is of particular interest as it has capability of providing solutions to some of these issues (Moon and Ngai 2008).

Barcode systems, although used for product information, inventory control, have some drawbacks as compared to RFID (Delen et al. 2007; Kärkkäinen 2003). The amount of information stored in a barcode is very less as compared to RFID. RFID can store up to 1,000 bytes of data. An RFID is specific to each item, whereas the barcode is not. Barcode needs human interaction for proper operation. It requires time-of-sight access to an optical scanner for the product related information. The barcode is to be replaced if the information it contains needs modification, but in RFID it can be modified at stages of the supply chain by the interaction between the microchip and the reader software. The barcode system is less accurate as compared to RFID.

While the use of RFID systems can improve the productivity and efficiency, they also expose new threats to the security and privacy of individual organisations (Phillips et al. 2005; Bogdanov et al. 2008; Ayoade 2007). The attackers can easily use duplicate tags to provide wrong information or can break the security algorithm or can modify the message. Hence, research and development should focus on resolving these issues. The other major problem associated with RFID is the lack of standardization as there are varieties of RFID tags (Michael and McCathie 2005; Goodrum et al. 2006; Bunduchi et al. 2011). The effort of governing bodies to develop various standards related to their use, manufacture and technical specification can help to resolve the issues related to 
standardization. In addition, the technological developments and innovations in information technology will also assist in this direction to achieve wide adoptability of RFID tags.

Although several RFID research publications focused on various applications of RFID, there is a dearth of review of the literature on the application of RFID in textile and clothing manufacturing and retailing. Hence, an attempt has been made in this paper to review various applications of RFID in the textile and clothing, manufacture and distribution. This paper also covers the technology of RFID, major challenges faced by the technology and the future directions.

\section{RFID systems}

\section{Technology of RFID system}

Radio frequency identification is an automatic identification method consisting of several components such as tags, tag readers, edge servers, middleware, and application software (Nayak et al. 2007; Rao et al. 2005; Chao et al. 2007). Among these the three important components are RFID tag (also known as transponder), RFID reader (also known as transceiver or interrogator) and software for data processing. An RFID tag is a small object that can be attached to or embedded into a product, animal, or person. It consists of a tiny chip where the data is stored and an antenna to enable it to receive and respond to radio-frequency queries from an RFID transceiver (See Figure 1). The tags contain electronic product code (EPC) and the information related to the product like the name of the company, batch and year of manufacturing, price etc. (Sarma et al. 2001; Myny et al. 2010).

There are four main frequency bands for RFID tags commonly in use. They are categorized by their radio frequency: low frequency tags (125 or $134.2 \mathrm{kHz})$, high frequency tags $(13.56 \mathrm{MHz})$, UHF tags $(868-956 \mathrm{MHz})$, and microwave tags $(2.45$ or $5.8 \mathrm{GHz})$. RFID tags can be either active, semi-passive (i.e. semi-active) or passive (Nayak et al. 2007; Tesoriero et al. 2008; Rao et al. 2005; Costin et al. 2012). Various applications of RFID according to the frequency band are discussed in Table 1.

\section{Types of RFID systems}

Passive RFID tags have no internal power supply. The minute electrical current induced in the antenna by the incoming radio frequency signal provides just enough power for the

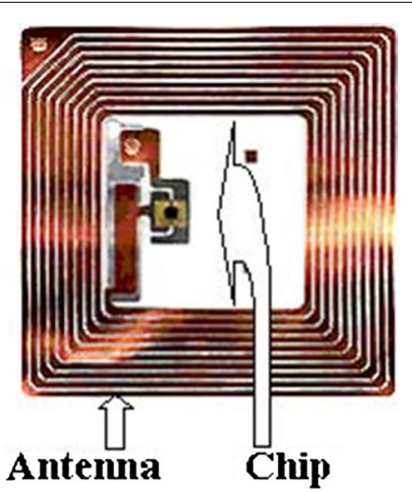

Figure 1 A RFID tag with chip and antenna. 
Table 1 RFID frequency bands and various applications

\begin{tabular}{|c|c|c|}
\hline Frequency band & Features & Applications \\
\hline $100-500$ kHz (low) & $\begin{array}{l}\text { Short to medium read range; inexpen- } \\
\text { sive; low reading speed }\end{array}$ & $\begin{array}{l}\text { - Access control; animal identification; } \\
\text { inventory control; car immobilizer }\end{array}$ \\
\hline 10-15 MHz (intermediate) & $\begin{array}{l}\text { Short to medium read range; poten- } \\
\text { tially inexpensive; medium reading } \\
\text { speed }\end{array}$ & $\begin{array}{l}\text { Access control; smart cards; library } \\
\text { control }\end{array}$ \\
\hline 850-950 MHz, 2.4-5.8 GHz (high) & $\begin{array}{l}\text { Long read range; high reading speed; } \\
\text { line of sight required; expensive }\end{array}$ & $\begin{array}{l}\text { Railway vehicle monitoring; toll col- } \\
\text { lection systems; pallet and container } \\
\text { tracking; vehicle tracking }\end{array}$ \\
\hline
\end{tabular}

Data taken from radio frequency identification-a basic primer, Association for Automatic Identification and Mobility, August 2001, http://www.aimglobal.org and from Wikipedia Encyclopedia, http://en.wikipedia.org/wiki/RFID.

integrated circuit (IC) in the tag to power up and transmit a response (Bouet and Dos Santos 2008). Most passive tags signal by backscattering the carrier signal from the reader. This means that the aerial (antenna) has to be designed to both collect power from the incoming signal and also to transmit the outbound backscatter signal. The tag chip can contain nonvolatile EEPROM (Electrically Erasable Programmable Read-Only Memory) for storing data (Barnett and Liu 2008). Lack of an onboard power supply means that the device can be quite small: commercially available products exist that can be embedded under the skin. As of 2005, the smallest such devices commercially available measured $0.4 \mathrm{~mm} \times 0.4 \mathrm{~mm}$, and is thinner than a sheet of paper; such devices are practically invisible. Passive tags have practical read distances ranging from about $2 \mathrm{~mm}$ up to about few metres depending on the chosen radio frequency.

Semi-passive RFID tags are very similar to passive tags except for the addition of a small battery (Zhang and Amin 2006). This battery allows the tag IC to be constantly powered ( $\mathrm{Li}$ et al. 2009). This removes the need for the aerial to be designed to collect power from the incoming signal. Aerials can therefore be optimised for the backscattering signal. Semi-passive RFID tags are faster in response as compared to passive tags. Active RFID tags or beacons, on the other hand, have an internal power source which is used to power any ICs and generate the outgoing signal (Ni et al. 2004; Jin and Lu 2006). They may have longer range and larger memories than the passive tags, as well as the ability to store additional information sent by the transceiver. At present, the smallest active tags are about the size of a coin. Many active tags have practical ranges of tens of metres, and a battery life of up to 10 years. As passive tags are cheaper to manufacture and have no battery, the majority of RFID tags in existence are of this variety.

\section{Working of an RFID systems}

The reader communicates with a tag, which contains digital information (Figure 2). A collection of wired and wireless network constitutes the communication infrastructure that carries out a series of information transfer actions to deliver the data stored in a tag to the reader. Readers are just like the barcode sensors, which broadcast a radio signal through the antenna to the tag. The tag then responds to the radio wave, and the data can be read from the chip of the tag. The tags can consist of read only memory (ROM), volatile read/ write random access memory (RAM) or write once/read many memory (WORM) for data storage (Jin and Lu 2006). ROM is used to store security data, whereas RAM is used for 




storing the data during transponder interrogation and response (Dimitriou 2005). The data consists of: (a) a unique identifier, (b) an operating system, (c) data storage (volatile/nonvolatile), and (d) an EPC.

Simultaneously data from multiple tags can be studied. Readers also decode the signal provided by the tags and transmit to the CPU. Suitable Software receives and interprets the information collected form the tags and stores it. Simultaneously multiple data can be collected and stored with much accuracy as compared to the existing barcode systems.

\section{Applications of RFID in fashion industry}

In the field of Textile and Apparel the RFID is used in manufacturing, inventory control, warehousing, distribution, logistics, automatic object tracking and supply chain management (Legnani et al. 2011; Liu et al. 2010; Moon and Ngai 2008; Gimpel et al. 2004). For example, the finished garments, different pattern pieces and accessories can be traced and the progress of the production process can be monitored. In processing and weaving, the fabric lots can be traced easily. In spinning mills, the bales of cotton and the yarns can be traced easily. The mixing of different yarn lots which is a major problem in spinning mills can be avoided.

A range of problems unique to fashion industry can be solved by installing the RFID system in various processes involved in fashion supply chain. Fashion industry can be divided into four sectors such as manufacturing, overseas transportation, distribution and retailing. In manufacturing RFID can be used to avoid product and component mixing, and mixing of different accessories. In overseas transportation RFID can be used to track and trace the consignment before and after Free on Board, if product is outsourced. RFID primarily can solve the issue of sorting and tracking the product very quickly, thus reducing the lead time during distribution (Moon and Ngai 2008). In majority of the retail shops, the space is a constraint, which needs to be used efficiently. RFID is used to manage the stock to identify the item quickly and correctly so as to avoid "search regret", and thus help to solve the problem (Reynolds et al. 2006).

\section{Inventory management}

The use of RFID system assists in better inventory management and enhances customer shopping experience (Hardgrave et al. 2009; De Kok et al. 2008). The RFID system can 
indicate the type of clothing selling faster or slower, which provide customized advertisement on picked clothes according to the RFID tags. The RFID use also helps in reducing labour. For example, American Apparel applied RFID system in eight of their stores, which saved about $60-80 \mathrm{~h}$ per week in labor and reduced out-of-stock products owing to unawareness. Similarly, the Japanese apparel manufacturer 'Sankei' is using a RFID system in manufacturing to track clothes during the manufacturing process in addition to the online sales (Wu et al. 2009).

A successful case study has been conducted by Kaufhaulf departmental store in Europe on the impact of RFID on their processes and supply chain (Loebbecke and Huyskens 2008). They have concluded that RFID can be used in warehousing to track the goods and assist in cross docking operation as the goods received are not segregated in the warehouse but stored as they are received from the manufacturer. In the distribution center's receivable area RFID readers can be implemented to track the goods as they come in. The received goods are registered and the data stored on RFID transponders can be read for each good though received in pallets or individual fashion item on hanger. In this the task of counting hangers, items and pallets can be eliminated and quantity can be controlled up to $100 \%$ satisfaction level.

\section{Production control}

Inside the stores of the production department the stock level can be quickly monitored which helps in a real-time and efficient inventory management (Wang et al. 2006; Lee et al. 2013; Jihui et al. 2011). The location and movement of the components, semi-finished and the finished products can be detected by the RFID system, which helps in production monitoring and control. The performance of departments and the individuals can be evaluated by the rate of movement of the garment components from the departments or individuals. This helps in improving the productivity and the quality. In the packing floor the mixing of different styles and sizes can be avoided by RFID tags. Also the number of pieces in packed cartons can be counted without opening, which saves the time and labour.

\section{Retail management}

It can be used in retail to monitor and control the floor level out-of-stocks (OOS) (Roussos 2006; Chen and Pfleuger 2008). It is mostly required where there is high product display density, low staffing level and chances of mishandling is very high. The stock level of the items is properly maintained and the items can be grouped according to their demand. Similarly, while receiving the goods at the store the accuracy of the deliveries can be ensured quickly with less labour. This can improve the inventory accuracy and automatic replenishment of stock. Mostly the retailers verify the accuracy and integrity of the shipment by open-box audit prior to stocking or storing of goods. But now it is possible to read all the items packed inside the carton without opening, which saves time and labour cost. So the RFID provides a new horizon to the retailers in receiving of materials, which eliminates the invoice disputes, mixing of different quality products etc.

The RFID has been used by number of major retailers in Europe and USA. Walmart is among the early adopters of RFID throughout their supply chain and the suppliers working with Walmart had been under pressure to implement RFID in their supply chain component as well. The reason of implementing RFID is line with Walmart's corporate 
strategy of being cost competitiveness and faster response (Vowels 2006). After successfully implementation and use of RFID by Walmart, other big retailers like Marks and Spencer and Tesco in UK are adopting it, Coles group in Australia have given a thought of embracing this technology. Fashion industry is always regarded as the late adopter of new technology than others, but in adopting RFID it is not lagging behind.

The theft of garments from the fitting room can be prevented by mounting a small reader at the entry point of the room. The tag information of the garment is captured when the customer takes the garment to the fitting room. The items that are taken to the fitting room but not come out are reported as potential loss items. So the RFID can be used to identify the missing merchandise and prosecution of the shoplifters (Rekik et al. 2008; Jaselskis et al. 1995). In addition, the dislocation of the clothes is automatically detected and customers can be given advice on the fitting of the clothes they are trying on. The later task can be achieved by the use of smart try-out cabins and smart mirrors. The smart mirror can advise on additional clothing and fashion accessories (Roberti 2006). Companies such as Marks and Spencer, Levi Strauss \& Co. are installing RFID to acquire data on the amount of stocks every day so that the stock can be replenished. However, significant difference was observed between the data received from the RFID systems and the actual inventory levels.

The store merchandise recovery and replenishment process presently used is completely manual, unsystematic and ineffective. Also it requires a very long time and high labour force and some popular items are not replenished for weeks. This can be overcome by RFID technology. The tags help to estimate the stock level frequently and there is an in-stock position improvement up to $30 \%$. This has a positive impact on sales and customer satisfaction. It prevents the fashion or the seasonal merchandise to lie undetected in the back room and to be sold at significant markdowns thus improving the profit margin.

Also at the point of sales the RFID tag can be read quickly and it avoids the physical handling of the product as in barcode system. The RFID tags can be placed at the side seams or hem or in a paper cartoon label without affecting the aesthetic appeal of the garment. The number of items sold is automatically adjusted from the amount of stock. Hence, the customers can be informed about the status/stock of merchandise by interactive display screens. The use of RFID tags has helped to reduce the out of stock rate of Wal-mart by $16 \%$ and RFID enabled stores were $63 \%$ more effective in replenishing outof-stocks than control stores (Age 2005).

\section{RFID for brand segregation}

It will be quite beneficial to adopt RFID system for departmental stores, which stocks a range of products and brands under one roof (Loebbecke and Huyskens 2008). The different brands can be controlled in terms of their inventory and location quite easily using RFID whereas it would be quite challenging task to segregate the brands in case they are mixed. RFID also reduces the human error as this technology is least human dependent when monitoring the inventory level, brand identification and product authenticity.

Radio frequency identification can also be used to avoid illegal product alteration to grey market and increasing product security and to give information about shopping 
behavior of customer at retail. Having all these issues solved, textile and fashion supply chain can be made more streamlined and efficient in terms of cost and performance.

\section{RFID used in fitting room}

Radio frequency identification technology is used in the fitting room in a new approach by a German departmental store "Galeria Kaufhof in Essen", (part of the Metro retailing group). Automatic suggestions are provided to men buying clothes in the store when they go to a dressing room to try a suit. A 'smart mirror' informs them what kind of suit or accessories will be appropriate. An RFID reader on the smart mirror in the fitting room determines which clothing has been brought into the room from the RFID tag attached to the apparel. The appropriate accessories are then displayed on a suitable interface. This system is used in combination with 'smart shelves', which can read what merchandise is currently in stock, so that customers can be shown various styles and sizes that are available.

\section{RFID tags for care labelling}

The recent care labels are printed or woven labels storing a limited information (Nayak and Padhye 2014, 2015b). The electronic labels use RFID tags for storing information electronically on a garment. The same RFID tag used for containing the product details at the point of sale cannot be used for storing the wash care instructions, due to the privacy concerns. Hence, additional tags are needed for the wash care instructions, which will increase the cost of the garment. In addition, the consumers need special readers to extract the information stored in the RFID tag. Hence, they will prefer the physical label instead of an electronic label. Furthermore, the use of RFID tags in the garment, may pose health risks to the consumers due to the exposure to radiation.

The other concern related to the use of RFID tag is the electronic waste. An appropriate method should be devised to recycle or reuse the RFID tags, if they are removed at the point of sale. Similarly, if customers remove the chip at some point, proper disposal of the tags is essential, which causes additional worries to the companies. In addition, the other issues related to RFID are the lack of standardisation and high cost. Standardising the technology, design and use of the tags can solve the issues related to lack of standardisation, whereas the technological developments can help to overcome the cost related issues.

Radio frequency identification tags can be used in combination with the registered identification number (RN) system, which is currently in use in some places including the USA. The Federal Trade Commission (FTC) issues the RN, which can be used on the textile label instead of the company name. The use of RN system assists the buyers to easily identify a company from the RN using internet. The RN system uses less space on the label and more space is available for other care instructions. Therefore, the combined use of RFID and RN number systems could further benefit industry and consumers.

The use of RFID tags is still in its infancy stage. Hence, it is too early to conclude the final shape of RFID tag and its impact on consumers. One of the industry observed benefits to the consumers by including washing instructions in the tag. In Germany, RFID chips are being used in nursing homes to help the nurses in correctly sorting the garment according to care instructions. Hence, there is a potential benefit of RFID tags to 
the consumers. However, all the major drawbacks should be overcome to make RFID tags a success.

\section{Customer relationship management}

It is quite imperative to understand the needs and taste of customers especially in fashion industry to offer them the right product of their match. Moon and Ngai (2008) conducted a study on the use of RFID in fashion retailing and reflected that different customers behaved different at different time in their shopping experience and knowing them in depth regarding their shopping experience was very important so that sales personnel could provide them with personalized services. The interviewee in their study said that if the customer entered into the store and picked few item connected to RFID technology that would provide signal of their pattern of choices on that day so tailored advice can be provided by sales staff. As competition is intense between the brands so it is important to satisfy the customers by knowing their choice by creating their history of purchases, especially for high-end products. By creating their profile, age group, choice trend, preferred styles etc. the professional suggestion can be provided upon their next purchase so that they feel taken care of. Other significance of using RFID is to be in constant contact with VIP customers, even if the staff member quits the job.

As customers preferences are different so as their buying behavior and pattern, RFID can be used to interact product with the consumer to suit their choices and assist them making purchase decision (Nayak et al. 2015). Subsequently the customers can be offered customized assistance to cater to their choices thus increasing the revenue.

Intelligent clothes racks and smart shelves allowed Kaufhof to gain additional intelligence about the customers' shopping and buying behaviours, which could then be used for further improving product and service offerings. Intelligent clothes racks were equipped with an RFID antenna. Each time a customer or employee removed a fashion item equipped with an RFID transponder from the rack, the movement was automatically entered into the merchandise management system. The moment the article was returned was also registered. The time that lapsed before a customer returned an item to the rack provided valuable information: If a customer put a blouse back on the clothes rack after $5 \mathrm{~s}$, she possibly did not like the material. If $5 \mathrm{~min}$ went by, it is likely that the customer tried on the article. Smart Shelves offered similar functionalities for stacked goods.

\section{Challenges to RFID}

Although RFID technology has already been applied effectively, have certain technological barriers that still need to be overcome to optimize its application. These lacunas are high investment, lack of security and privacy, and some related to the technology of RFID (Wu et al. 2006; Jones et al. 2005; Welbourne et al. 2007).

\section{High cost}

Although there is a great potential of RFID in the local logistics sector, the major drawback is the cost of the RFID tag is higher as compared to barcode system (Ohkubo et al. 2005, Jones et al. 2005). Therefore, industrial leaders are concerned about the return on investment and net profit by investing the extra cost into the existing system. The cost depends 
on the volume of usage. The lowest cost tags available on the market are as low as 7.2 cents each in volumes of 10 million units or more. The average cost of a RFID tag is around $30-40$ cents if the volume is not sufficiently large but the cost is only 4 cents for a barcode. The companies like Wall-mart, Benetton, and Prada are trying to still reduce the price. After the price is reduced all the retailers and manufacturers can implement the technology. Apart from the initial cost, there is cost involved in maintenance and up keeping of the system. But RFID tags will completely replace the barcode system in future.

The use of RFID in supermarkets is worthwhile because the transactions speed in supermarket should be fast and prompt to reduce the queuing time whereas in fashion industry the purchase is not in bulk so transaction speed is not very relevant in fashion industry. So the cost of using RFID tags for economical/low-priced clothes will impact significantly on the final cost of the garment. But where quick scanning is required in case of larger purchases and promptly replenishing merchandise, the use of RFID is very important and trustworthy.

\section{Security and privacy issues}

The security and privacy of the RFID against unauthorized readers is in debate from the very beginning (Sarma et al. 2003; Peris-Lopez et al. 2006; Gao et al. 2004). There is a great challenge to the consumer privacy. The consumers using the product with RFID tags can be traced easily. The RFID tag broadcasts the ID serial number or the EPC to the nearby reader. There is a very high chance of privacy violations. The size of the dress a woman wants can be publicly readable by any nearby scanner. Due to this problem the cloth retailer Benetton has planned to withdraw the use of RFID tags in its apparel products. CASPIAN (Consumers against Supermarket Policy Invasion and Numbering) group, based in US has claimed that RFID tags embedded in items can track the consumers creating unwanted surveillance and an invasion of privacy.

Many security measures have been proposed for RFID in various literatures to overcome the above problem (Peris-Lopez et al. 2006; Osaka et al. 2006). The simplest is the "Kill Tag" approach in which the tag is electronically deactivated after the item is being sold out. The tag also can be removed physically from the product before they are placed on the hand of the consumers. The other approaches are Cryptographic approach, Hash Function approach, Faraday Cage approach, Randomized Hash Lock, backward channel XORing, Active Jamming approach, Regulation approach etc.

\section{RFID attacks}

Tag damage

The RFID tags can be damaged by attackers or due to the improper handling of the material. This attack in turn can prevent the data communication with the reader.

\section{Fake tags}

The attackers may replace the original tags with fake ones, which will prevent the data transfer or provide fake information to $t$ the reader. 


\section{Security attacks}

The attackers can break the security algorithm used in the RFID system or modify the message in the reader.

\section{Compatibility}

A lot of time and money is needed to set up the RFID systems, which may not be economical for many companies. Furthermore, RFID may not be compatible with some existing technologies and even if it can be integrated with existing system the expectancy of $100 \%$ data accuracy is still a matter of concern (Smart et al. 2010; Lee and Chan 2009). This becomes more important when the suppliers and buyers have to deal with their overseas counterparts. Some companies are afraid of using the RFID technology as the high investment may be replaced by some other technologies as the technological advancements in near future may bring better technologies than RFID.

\section{Technology}

As the RFID is based on the concept of Radio Frequency, it can be interfered with other radio transmissions, metals, liquids etc. (Bunduchi et al. 2011; Wu et al. 2006; Ni et al. 2011). The degree of interference depends upon the frequency of the tag and the usage environment, which may lead to inaccurate reading. For example the use of RFID readers to read the price tags of purchased merchandise at the checkout counters may be interfered by radio waves from other merchandise. In addition, the merchandise are made in different countries and may be packed with different material.

\section{Lack of standardization}

Radio frequency identification is at the infancy stage and there are many hurdles ahead of it. There are many versions of RFID that operate at different frequencies and need different software and readers. So the need is to be agreed upon one or group of frequencies to have interoperability between the manufacturers, retailers and distributors. Currently, two organisations: EPC global and International Standards Organization (ISO) are working to standardize the use of RFID in UHF spectrum (Wu et al. 2006). Although, standards such as EPC class 1 G2 protocol and ISO 18000-6 are being released, both the standards are yet not finalised and lack compatibility with each other.

\section{Research on RFID}

Various research have been done on the technology including tags, antennae and readers of RFID (Nikitin et al. 2005; Ukkonen et al. 2012; Kellomäki et al. 2012; Occhiuzzi et al. 2010; Gimpel et al. 2004); communications infrastructure (Srivastava 2010; Zuo 2010; Welbourne et al. 2007); logistics (Wang and Wang 2009; Kapoor et al. 2009); security (Fishkin et al. 2005; Simson et al. 2005; Thiesse 2007; Yeo and Kim 2005; Knospe and Pohl 2004); and standardization (Moon and Ngai 2008; Bolic et al. 2010).

Although several challenges are present for the adoption of RFID, they can be overcome with the technical developments. Similar to other emerging technologies, RFID will become a reality in fashion and textiles over time. Research and development can help in mitigating the associated problems with the use of RFID. The technological issues such as $100 \%$ reliability can be achieved by: (1) installing multiple antennas 
with different orientations per reader, (2) customizing the tag and antenna design for each material type and (3) installing multiple readers to increase readability of the tags. Reading multiple tags simultaneously is possible by the use of binary search technique. Repetition of reading the tags can be avoided by putting the tags already read into sleep mode. Research and development will help in maximizing the antenna power pattern and the chances of successful reading (Weber 2010).

Research is needed to explore how RFID technology can be used to improve the inventory management performance by reducing forecast error and inventory discrepancy. Various models need to be developed to establish a suitable benchmark for calculating the value of the RFID system to improve the inventory management (Burmester and De Medeiros 2007; Nayak and Padhye 2011). Research is needed to manage inventory operations in a supply chain where both the systems (bar coding and RFID) are working.

Furthermore, for successful application of RFID, existing research should focus on a host of disciplines, such as electronic engineering, information systems, computer science, and business strategy (Bhattacharya et al. 2007). Prior to the research and development, it is vital to determine the principal concerns of RFID, whether technological, application related, or security related. Maintaining security of the RFID tags is a challenging job. The improvement in information technology and design of smart RFID tags can help to overcome this challenge.

\section{Conclusion and future trends of RFID in apparel industry}

The use of RFID systems in textiles is rapidly increasing. In future almost all the manufacturers, distributors and retailers in textile business will be using the RFID system. Although, RFID systems cannot completely replace the barcode technology, due to higher cost but the accuracy, speed and the return on investment is high in RFID system. RFID system is a promising technology, which will become ubiquitous in the future helping organizations to solve problems in supply chain management, security, personal identification and object tracking.

The retailers, manufacturers and consumer goods companies like CVS, Tesco, Prada, Benetten, Wal-mart and Procter \& Gamble now implementing the technology and exploring the impact of the technology on their business. Others can take the advantages of RFID. The basic of success lies in understanding the technology and other features to minimize the potential problems. It is high-time that the apparel industries should start utilizing the new RFID technology in various applications such as manufacturing, storing purposes.

There is a great potential of RFID in various applications relater to clothing and textiles, manufacturing, retailing and inventory management. The direct benefits have been shown by the companies such as GAP, the US apparel company, who increased their sales by $2 \%$ by using RFID to reduce stock-outs. Another well-known US apparel company, J Crew, increased the speed of inventory keeping time five to eight times by the use of RFID.

The apparel industry is characterized by short product life cycle, frequent style changes, a wide range of product designs and hence input materials; variable production volumes; high competitiveness and often high demand on product quality. In addition to these challenges, the use of RFID increases the cost and maintaining privacy creates 
extra challenges. The organizations dealing with textile and apparel products should start with the tracking of expensive goods as the reduction in the labor and theft of these items can compensate the cost of these items. RFID has advantages in speed, accuracy and convenient over traditional barcode systems. Therefore, in the future, RFID tagging will gradually replace traditional barcode systems and facilitate supply chain and inventory management.

Important technical challenges still need to be resolved for fully successful operation of RFID in textile and apparel manufacturing. It will take some years may be a decade or so, before the full benefits of RFID technology is realized. We will increasingly see how RFID technology can extend the ability of computers in combination with internet to sense and respond to the physical world. In future, RFID will make computing an unobtrusive, intuitive part of everyday life, as refreshing as a walk through the nature.

The largest challenge to the widespread use of RFID is the cost in textile and apparel manufacturing. These challenges can be reduced by increasing the volume of usage. In addition standardization and technological developments can help in reducing the cost. RFID chips can be developed, which can work in different places for different applications. These ideal RFID chips will require a frequency independent capability and would be integrated with read/write memory. In addition, the software needs to be customized to accommodate the number of different uses. Recently, all the merchandise uses the barcodes for identification and at the point of sale, which are easily printed and attached to the products within a very short period. However, finalization of the design and preparation of RFID tags is time consuming process.

The issues related to standardization can be resolved by the effort of governing bodies to develop various standards related to their use, manufacture and technical specification. Technological developments will also assist in this direction to achieve wide adoptability of RFID tags. In addition, throughout a supply chain RFID-friendly infrastructure development is a time consuming process.

From the above discussions, it is clear that RFID technology has a very bright future in the textile and clothing industry. New areas of applications will emerge by the technical advancements and we will see more RFID applications in departments where they are currently not being used. This paper will be a good resource for those interested in RFID research, including academic researchers and industry practitioners, and will provide guideline to stimulate further interest in this area.

Authors' contributions

RN designed the paper, performed the literature survey and completed the paper. AS completed the application of RFID in textile and fashion retailing section and helped in feedback and comments. RP and LW guided during the paper design and helped in feedback and comments in final format of the paper. All authors read and approved the final manuscript.

Compliance with ethical guidelines

Competing interests

The authors declare that they have no competing interests.

Received: 1 January 2015 Accepted: 27 May 2015

Published online: 27 June 2015 


\section{References}

Age, C. S. (2005). Research confirms Wal-Mart's RFID benefit. Chain Store Age, 81, 80.

Ayoade, J. (2007). Roadmap to solving security and privacy concerns in RFID systems. Computer Law \& Security Review, 23, $555-561$.

Bagchi, U., Guiffrida, A., O'Neill, L., Zeng, A., \& Hayya, J. (2007). The effect of RFID on inventory management and control. Teends in supply chain design and management. New York: Springer.

Barnett, R. E., \& Liu, J. (2008). An EEPROM programming controller for passive UHF RFID transponders with gated clock regulation loop and current surge control. IEEE Journal of Solid-State Circuits, 43, 1808-1815.

Bhattacharya, M., Chu, C. H., \& Mullen, T. (2007). RFID implementation in retail industry: Current status, issues, and challenges. In Proceedings of 38th Annual Meeting of the Decision Sciences Institute, Phoenix, AZ, 2007 (pp. 2171-2176). Citeseer.

Bogdanov, A., Leander, G., Paar, C., Poschmann, A., Robshaw, M. J., \& Seurin, Y. (2008). Hash functions and RFID tags: Mind the gap. Cryptographic hardware and embedded systems (CHES 2008). New York: Springer.

Bolic, M., Simplot-Ryl, D., \& Stojmenovic, I. (2010). RFID systems: Research trends and challenges. Hoboken: Wiley.

Bottani, E., Ferretti, G., Montanari, R., \& Rizzi, A. (2009). The impact of RFID technology on logistics processes of the fashion industry supply chain. International Journal of RF Technologies: Research and Applications, 1, 225-252.

Bouet, M., \& Dos Santos, A. L. (2008). RFID tags: Positioning principles and localization techniques. In Wireless Days, 2008 (WD'08), 1st IFIP, 2008 (pp. 1-5). IEEE.

Bunduchi, R., Weisshaar, C., \& Smart, A. U. (2011). Mapping the benefits and costs associated with process innovation: The case of RFID adoption. Technovation, 31, 505-521.

Burmester, M., \& de Medeiros, B. (2007). RFID security: Attacks, countermeasures and challenges. In The 5th RFID Academic Convocation, The RFID Journal Conference. http://www.cs.fsu.edu/ burmeste/133.pdf.

Chao, C. C., Yang, J. M., \& Jen, W. Y. (2007). Determining technology trends and forecasts of RFID by a historical review and bibliometric analysis from 1991 to 2005. Technovation, 27, 268-279.

Chen, J. V., \& Pfleuger Jr, P. (2008). RFID in retail: A framework for examining consumers' ethical perceptions. International Journal of Mobile Communications, 6, 53-66.

Christopher, M., Lowson, R., \& Peck, H. (2004). Creating agile supply chains in the fashion industry. International Journal of Retail \& Distribution Management, 32, 367-376.

Costin, A., Pradhananga, N., \& Teizer, J. (2012). Leveraging passive RFID technology for construction resource field mobility and status monitoring in a high-rise renovation project. Automation in Construction, 24, 1-15.

de Kok, A., van Donselaar, K., \& van Woensel, T. (2008). A break-even analysis of RFID technology for inventory sensitive to shrinkage. International Journal of Production Economics, 112, 521-531.

Delen, D., Hardgrave, B. C., \& Sharda, R. (2007). RFID for better supply-chain management through enhanced information visibility. Production and Operations Management, 16, 613-624.

Dimitriou, T. (2005). A lightweight RFID protocol to protect against traceability and cloning attacks. In First international conference on security and privacy for emerging areas in communications networks, 2005 (SecureComm 2005) (pp. 59-66). IEEE.

dos Santos, B. L., \& Smith, L. S. (2008). RFID in the supply chain: Panacea or Pandora's box? Communications of the ACM, 51, $127-131$.

Dutta, A., Lee, H. L., \&Whang, S. (2007). RFID and operations management: Technology, value, and incentives. Production and Operations Management, 16, 646-655.

Fishkin, K. P., Roy, S., \& Jiang, B. (2005). Some methods for privacy in RFID communication. Security in ad-hoc and sensor networks. New York: Springer.

Gao, X., Xiang, Z., Wang, H., Shen, J., Huang, J., \& Song, S. (2004). An approach to security and privacy of RFID system for supply chain. In IEEE international conference on e-commerce technology for dynamic e-business, 2004 (pp. 164-168). IEEE.

García, A., Chang, Y., Abarca, A., \& Oh, C. (2007). RFID enhanced MAS for warehouse management. International Journal of Logistics, 10, 97-107.

Gimpel, S., Mohring, U., Muller, H., Neudeck, A., \& Scheibner, W. (2004). Textile-based electronic substrate technology. Journal of Industrial Textiles, 33, 179-189.

Goodrum, P. M., McLaren, M. A., \& Durfee, A. (2006). The application of active radio frequency identification technology for tool tracking on construction job sites. Automation in Construction, 15, 292-302.

Hardgrave, B. C., Aloysius, J., \& Goyal, S. (2009). Does RFID improve inventory accuracy? A preliminary analysis. International Journal of RF Technologies: Research and Applications, 1, 44-56.

Jaselskis, E. J., Anderson, M. R., Jahren, C. T., Rodriguez, Y., \& Njos, S. (1995). Radio frequency identification applications in construction industry. Journal of Construction Engineering and Management, 121, 189-196.

Jihui, G., Fuhai, L., Bing, D., Peng, W., \& Lehong, H. (2011). A design of RFID tag antenna for clothing. In Cross Strait QuadRegional Radio Science and Wireless Technology Conference (CSQRWC), 2011 (pp. 1075-1077). IEEE.

Jin, G. Y., Lu, X. Y., \& PARK, M. S. (2006). An indoor localization mechanism using active RFID tag. In IEEE International conference on sensor networks, ubiquitous, and trustworthy computing, 2006 (p. 4). IEEE.

Jones, P., Clarke-Hill, C., Hillier, D., \& Comfort, D. (2005). The benefits, challenges and impacts of radio frequency identification technology (RFID) for retailers in the UK. Marketing Intelligence \& Planning, 23, 395-402.

Kapoor, G., Zhou, W., \& Piramuthu, S. (2009). Challenges associated with RFID tag implementations in supply chains. European Journal of Information Systems, 18, 526-533.

Kärkkäinen, M. (2003). Increasing efficiency in the supply chain for short shelf life goods using RFID tagging. International Journal of Retail \& Distribution Management, 31, 529-536.

Kellomäki, T., Virkki, J., Merilampi, S., \& Ukkonen, L. (2012). Towards washable wearable antennas: a comparison of coating materials for screen-printed textile-based UHF RFID tags. International Journal of Antennas and Propagation, 2012. doi:10.1155/2012/476570.

Knospe, H., \& Pohl, H. (2004). RFID security. Information Security Technical Report, 9, 39-50.

Landt, J. (2005). The history of RFID. Potentials, IEEE, 24, 8-11. 
Lee, C., \& Chan, T. (2009). Development of RFID-based reverse logistics system. Expert Systems with Applications, 36, 9299-9307.

Lee, C., Choy, K. L., Ho, G. T., \& Law, K. (2013). A RFID-based resource allocation system for garment manufacturing. Expert Systems with Applications, 40, 784-799.

Legnani, E., Cavalieri, S., Pinto, R., \& Dotti, S. (2011). The potential of RFID technology in the textile and clothing industry: Opportunities, requirements and challenges. In Unique radio innovation for the 21st century. New York: Springer.

Li, X., Zhang, Y., \& Amin, M. G. (2009). Multifrequency-based range estimation of RFID tags. In IEEE international conference On RFID, 2009 (pp. 147-154). IEEE.

Liu, J., Gao, W., Wang, H., Jiang, H., \& Li, Z. (2010). Development of bobbin tracing system based on RFID technology. The Journal of the Textile Institute, 101, 925-930.

Liu, F., \& Miao, Z. (2006). The application of RFID technology in production control in the discrete manufacturing industry. In IEEE international conference on video and signal based surveillance, 2006 ( AVSS'06) (p. 68). IEEE.

Loebbecke, C., \& Huyskens, C. (2008). A competitive perspective on standard-making: Kaufhof's rfid project in fashion retailing. Electronic Markets, 18, 30-38.

Michael, K., \& Mccathie, L. (2005). The pros and cons of RFID in supply chain management. In International conference on mobile business, 2005 (ICMB 2005) (pp. 623-629). IEEE.

Miles, S. B., Sarma, S. E., \& Williams, J. R. (2008). RFID technology and applications. Cambridge: Cambridge University Press.

Moon, K., \& Ngai, E. (2008). The adoption of RFID in fashion retailing: A business value-added framework. Industrial Management \& Data Systems, 108, 596-612.

Myny, K., Steudel, S., Smout, S., Vicca, P., Furthner, F., van der Putten, B., et al. (2010). Organic RFID transponder chip with data rate compatible with electronic product coding. Organic Electronics, 11, 1176-1179.

Nath, B., Reynolds, F., \& Want, R. (2006). RFID technology and applications. IEEE Pervasive Computing, 5, 22-24.

Nayak, R., Chatterjee, K., Khurana, G., \& Khandual, A. (2007). RFID: Tagging the new era. Man-Made Textiles in India, 50 , 174-177.

Nayak, R., \& Padhye, R. (2011). Application of modelling and simulation in smart and technical textiles. In A. Patanaik (Ed.), Modeling and simulation in fibrous materials: techniques and applications. Huntington: Nova Science.

Nayak, R., \& Padhye, R. (2014). The care of apparel products. In R. Sinclair (Ed.), Textiles and fashion: materials, design and technology. Kidlington: Elsevier.

Nayak, R., \& Padhye, R. (2015a). Introduction: The apparel industry. In R. Nayak \& R. Padhye (Eds.), Garment manufacturing technology. Cambridge: Elsevier.

Nayak, R., \& Padhye, R. (2015b). Care labeling of clothing. In R. Nayak \& R. Padhye (Eds.), Garment manufacturing technology. Amsterdam: Elsevier.

Nayak, R., Padhye, R., Wang, L., Chatterjee, K. \& Gupta, S. (2015). The role of mass customisation in the apparel industry. International Journal of Fashion Design, Technology and Education, 1-11.

Ni, L. M., Liu, Y., Lau, Y. C., \& Patil, A. P. (2004). LANDMARC: Indoor location sensing using active RFID. Wireless Networks, 10, $701-710$.

Ni, L. M., Zhang, D., \& Souryal, M. R. (2011). RFID-based localization and tracking technologies. Wireless Communications, IEEE, 18, 45-51.

Nikitin, P.V., Lam, S., \& Rao, K. (2005). Low cost silver ink RFID tag antennas. In Antennas and propagation society international symposium, 2005 (pp. 353-356) IEEE.

Nikitin, P.V., Parks, A., \& Smith, J.R. (2013). RFID-Vox: A tribute to Leon Theremin. In Wirelessly powered sensor networks and computational RFID. New York: Springer.

Occhiuzzi, C., Cippitelli, S., \& Marrocco, G. (2010). Modeling, design and experimentation of wearable RFID sensor tag. IEEE Transactions on Antennas and Propagation, 58, 2490-2498.

Ohkubo, M., Suzuki, K., \& Kinoshita, S. (2005). RFID privacy issues and technical challenges. Communications of the ACM, $48,66-71$

Osaka, K., Takagi, T., Yamazaki, K., \& Takahashi, O. (2006). An efficient and secure RFID security method with ownership transfer. In International conference on computational intelligence and security, 2006 (pp. 1090-1095). IEEE.

Peris-Lopez, P., Hernandez-Castro, J. C., Estevez-Tapiador, J. M., \& Ribagorda, A. (2006). RFID systems: A survey on security threats and proposed solutions. In Personal wireless communications, 2006 (pp. 159-170). New York: Springer.

Phillips, T., Karygiannis, T., \& Kuhn, R. (2005). Security standards for the RFID market. Security \& Privacy, IEEE, 3, 85-89.

Piramuthu, S., Wochner, S., \& Grunow, M. (2014). Should retail stores also RFID-tag 'cheap'items? European Journal of Operational Research, 233, 281-291.

Rao, K. S., Nikitin, P. V., \& Lam, S. F. (2005). Antenna design for UHF RFID tags: A review and a practical application. IEEE Transactions on Antennas and Propagation, 53, 3870-3876.

Rekik, Y., Sahin, E., \& Dallery, Y. (2008). Analysis of the impact of the RFID technology on reducing product misplacement errors at retail stores. International Journal of Production Economics, 112, 264-278.

Reynolds, K. E., Folse, J. A. G., \& Jones, M. A. (2006). Search regret: Antecedents and consequences. Journal of Retailing, 82, 339-348.

Roberti, M. (2006). RFID is fit to track clothes. Chain Store Age, 82, 158.

Roberts, C. M. (2006). Radio frequency identification (RFID). Computers \& Security, 25, 18-26.

Roussos, G. (2006). Enabling RFID in retail. Computer, 39, 25-30.

Sarma, S., Brock, D., \& Engels, D. (2001). Radio frequency identification and the electronic product code. IEEE Micro, 21, $50-54$.

Sarma, S. E., Weis, S. A., \& Engels, D. W. (2003). RFID systems and security and privacy implications. In Cryptographic hardware and embedded systems (CHES 2002). New York: Springer.

Simson, L., Juels, A., \& Pappu, R. (2005). RFID privacy: An overview of problems and proposed solutions. In IEEE symposium on security \& privacy, 2005 (pp. 34-43).

Smart, A. U., Bunduchi, R., \& Gerst, M. (2010). The costs of adoption of RFID technologies in supply networks. International Journal of Operations \& Production Management, 30, 423-447. 
Srivastava, B. (2010). Critical management issues for implementing RFID in supply chain management. International Journal of Manufacturing Technology and Management, 21, 289-307.

Sun, C. (2012). Application of RFID technology for logistics on internet of things. AASRI Procedia, 1, 106-111.

Tan, H. (2008). The application of RFID technology in the warehouse management information system. In International symposium on electronic commerce and security, 2008 (pp. 1063-1067). IEEE.

Tedjini, S., Perret, E., Vena, A., \& Kaddour, D. (2012). Mastering the electromagnetic signature of chipless RFID tags. In N. Chandra Karmakar (Ed.), Chipless and conventional radio frequency identification: Systems for ubiquitous tagging (pp. 146-174). IGl Global, USA

Tesoriero, R., Gallud, J., Lozano, M., \& Penichet, V. (2008). Using active and passive RFID technology to support indoor location-aware systems. IEEE Transactions on Consumer Electronics, 54, 578-583.

Thiesse, F. (2007). RFID, privacy and the perception of risk: A strategic framework. The Journal of Strategic Information Systems, 16, 214-232.

Ukkonen, L., Sydanheimo, L., \& Rahmat-Samii, Y. (2012). Sewed textile RFID tag and sensor antennas for on-body use. In 6th European conference on antennas and propagation (EUCAP), 2012 (pp. 3450-3454). IEEE.

Vowels, S. A. (2006). A straegic case for RFID: An examination of Wal-mart and its supply chain.

Wang, Z. G., Tang, R. Z., Sheng, W. L., \& Wang, G. D. (2006). Research on RFID-based production logistics management techniques with application in garment industry. In International technology and innovation conference, 2006 (ITIC 2006) (pp. 383-387). IET.

Wang, L., \& Wang, G. (2009). RFID-driven global supply chain and management. International Journal of Computer Applications in Technology, 35, 42-49.

Want, R. (2006). An introduction to RFID technology. Pervasive Computing, IEEE, 5, 25-33.

Weber, R. H. (2010). Internet of things-new security and privacy challenges. Computer Law \& Security Review, 26, 23-30.

Weinstein, R. (2005). RFID: A technical overview and its application to the enterprise. IT professional, 7, 27-33.

Welbourne, E., Balazinska, M., Borriello, G., \& Brunette, W. (2007). Challenges for pervasive RFID-based infrastructures.

In Fifth annual IEEE international conference on pervasive computing and communications workshops, 2007 (PerCom Workshops' 07) (pp. 388-394). IEEE.

Whitaker, J., Mithas, S., \& Krishnan, M. S. (2007). A field study of RFID deployment and return expectations. Production and Operations Management, 16, 599-612.

White, G., Gardiner, G., Prabhakar, G. P., \& ABD RAZAK, A. (2007). A comparison of barcoding and RFID technologies in practice. Journal of Information, Information Technology and Organizations, 2, 119-132.

Wu, D. L., Ng, W. W., Yeung, D. S., \& Ding, H. L. (2009). A brief survey on current RFID applications. In International conference on machine learning and cybernetics, 2009 (pp. 2330-2335). IEEE.

Wu, N. C., Nystrom, M., Lin, T. R., \& Yu, H. C. (2006). Challenges to global RFID adoption. Technovation, 26, 1317-1323.

Yeo, S. S., \& Kim, S. K. (2005). Scalable and flexible privacy protection scheme for RFID systems. In Security and privacy in ad hoc and sensor networks. New York: Springer.

Zhang, Y., \& Amin, M. G. (2006) Localization and tracking of passive RFID tags. In Defense and security symposium, 2006 (pp. 624809-624811). International Society for Optics and Photonics.

Zuo, Y. (2010). Survivable RFID systems: Issues, challenges, and techniques. IEEE Transactions on Systems, Man, and Cybernetics, Part C: Applications and Reviews, 40, 406-418.

\section{Submit your manuscript to a SpringerOpen ${ }^{\circ}$ journal and benefit from:}

- Convenient online submission

- Rigorous peer review

- Immediate publication on acceptance

- Open access: articles freely available online

- High visibility within the field

- Retaining the copyright to your article

Submit your next manuscript at $\mathbf{s p r i n g e r o p e n . c o m ~}$ 